\title{
FUNGSI DAN TEKNIK PERMAINAN ALAT MUSIK TRADISIONAL MANDAILING UYUP-UYUP DI DESA PARGARUTAN JAE TAPANULI SELATAN
}

\author{
EBEN EZER SILABAN \\ Prodi Pendidikan Musik
}

\begin{abstract}
This study aims to determine Function, Game Techniques and Organic Uyup-Uyup In Pargarutan Village Jae Tapanuli Selatan. The purpose of this research is to know the function, game technique and organology of mandailing uyup-uyup instrument in Pargarutan Jae Tapanuli Selatan Village community. The theory used is function, game technique and organology. The function of music is to express the taste and simultaneously as an activity of various types of human communication. Organology is the study of the structure of musical instruments based on sound sources, how to produce sounds and system of alignment. Game technique is a way or technique of touch on a musical instrument over a particular tone according to the instructions or notation. The method used in this research is qualitative descriptive method. The sample in this research is one artist and five people of Pargarutan Jae Village. Data collection was done by observation, interview, and documentation. This research was taken in Pargarutan Jae Village, and this research was carried out from October 2017. The function of Uyup-uyup music instrument in South Tapanuli there are three of the first is the function of emotional disclosure is a medium for someone to express feelings and emotional through the game of uyup-uyup instruments that use systematic way of presenting the sound. The second is the entertainment function in which the South Tapanuli also need entertainment that is the entertainment of playing a uyup-uyup instrument at rest in the rice fields. Third is the Communication Function where when calling the opposite sex across the paddy field the man repeatedly played uyup-uyup. Organic musical instrument Uyup-uyup consists of five parts, namely rice stalks, coconut leaves and lidi as a binder of coconut leaves. The game technique in the uyup-uyup instrument is divided into the first three sections that are played in a sitting / standing position, the second way of blowing uyup-uyup is by way of the mouth is placed at the base of the top of the uyup-uyup instrument, the third position of the finger finger, first starting from the left hand with the beginning of the index finger and the second hole of the middle finger and then on the right hand begins with the index finger and the hole of both middle fingers.
\end{abstract}

Keywords: Function, Game Technique, Uyup-Uyup Organic Studies

\section{PENDAHULUAN}

\section{A. Latar Belakang Masalah}

Keberagaman seni budaya yang ada di Indonesia memberi banyak pengaruh bagi peradaban manusia, demikian juga dengan seni musik. Alat musik tradisional membawa pengaruh yang sangat signifikan dalam perkembangan musik. Musik tradisional (etnis) adalah musik yang hidup tumbuh dan berkembangan atau lahir dari budaya setempat. Musik tradisional diwariskan secara turuntemurun dari generasi ke generasi yang berpadu dengan kegiatan sehari hari sesuai dengan kondisi sosial budaya serta alam daerah setempat. Mandailing merupakan suku yang lebih mayoritas di daerah Tapanuli Selatan, yaitu wilayah yang berada di 
Propinsi Sumatra Utara. Masyarakat

Tapanuli Selatan angat erat hubungannya dengan seni yang merupakan peninggalan nenek moyang, yaitu seperti seni tari, seni pahat dan seni tari. Чуир-иуир merupakan salah satu alat musik tradisional yang jarang diketahui masyarakat Mandailing bahkan banyak masyarakat desa Pargarutan Jae yang lupa cara membuatnya bahkan cara memainkannya khususnya muda-mudi yang berada di desa Pargarutan Jae.

Uyup-uyup sudah semakin minim karena semakin sedikit sekali pembuatannya dan kurangnya pengalaman dalam pembuatan alat musik Uyup-uyup. Faktor yang mungkin menyebabkannya yaitu kurangnya minat masyarakat di desa Pargarutan Jae khususnya muda-mudi akan alat musik tradisionalnya, dimana kalangan muda Pargarutan Jae lebih cenderung menyukai dan memainkan alat musik modern daripada mengenal dan mempelajari alat musik tradisional Mandailing khususnya Uyup-uyup. Latar belakang terciptanya alat musik ini karena tidak adanya hiburan setelah panen padi, akhirnya diperbuatlah alat musik uyup-uyup sebagai penghibur dari bahan dan pembuatan yang ringan dan memainkannya pun tidak membuang tenaga yang banyak. Pada zaman dahulu pada saat panen tiba, Uyup-uyup ikut menghibur masyarakat sesudah lelah menuai padi di sawah dan mempunyai makna tersendiri bagi si pemain Uyup-uyup . Ada rasa kepuasan setelah memainkan alat musik tersebut dan rasa syukur setelah panen padi. Uyupuyup berfungsi sebagai hiburan pribadi juga sebagai komunikasi di masyarkat mandailing yang artinya mengandung isyarat-isyarat tersendiri yang hanya diketahui oleh masyarakat yang sumber bunyinya berasal dari hembusan udara pada rongga (Aerofon). Dari uraian diatas, akan diangkat permasalahan dalam suatu penelitian yang berjudul "Fungsi dan Teknik Permainan Alat Musik Tradisional Mandailing Uyup-Uyup Di Desa Pargarutan Jae Tapanuli Selatan. tersebut. Hal ini dilihat dari melodi alat musik tersebut. Uyupuyup merupakan salah satu instrument musik kedalam klasifikasi alat musik aerofon. 


\section{B. Tujuan Penelitian}

1 Untuk mengetahui bagaimana fungsi alat musik tradisional mandailing Uуир-иуир di Desa Pargarutan Jae Tapanuli Selatan

2 Untuk mengetahui bagaimana teknik permainan alat musik tradisional mandailing Uyupuyup di Desa Pargarutan Jae Tapanuli Selatan

3 Untuk mengetahui bagaimana Organologi alat musik Uyupиуир.

4 Untuk mengetahui bagaimana tanggapan masyarakat terhadap alat musik tradisional mandailing Uyup-uyup di Desa Pargarutan Jae Tapanuli Selatan

\section{LANDASAN TEORI}

Landasan teoritis adalah sebuah dasar rujukan dalam sebuah penelitian. Dengan menggunakan teori-teori para ahli, maka sebuah penelitian akan bisa dilakukan dengan benar. Menurut pendapat Sugiyono (2010:57) bahwa "Landasan teori adalah untuk memperjelas masalah yang diteliti serta merumuskan hipotesis dan sebagai referensi untuk menyusun instrument penelitian".

\section{Teori Fungsi}

Dari berbagai jenis musik tersebut, Alan P. Merriam (1964) mengemukakan fungsi musik sebagai berikut:
a. Fungsi
Pengungkapan

Emosional

Musik berfungsi sebagai suatu media bagi orang untuk mengungkapkan perasaan atau emosi.

a. Fungsi Hiburan

Musik memiliki fungsi hiburan. Masyarakat pada umumnya sangat membutuhkan musik sebagai hiburan. Musik yang diciptakan untuk hiburan sengaja di desain sesuai kebutuhan masyarakat dilihat dari lirik atau melodinya yang mudah untuk dihafalkan

b. Fungsi Komunikasi

Musik memiliki fungsi komunikasi berarti bahwa sebuah musik yang berlaku di suatu daerah kebudayaan mengandung isyarat-isyarat tersendiri yang hanya 
diketahui oleh masyarakat pendukung kebudayaan tersebut. Hal ini dapat dilihat dari teks ataupun melodi musik tersebut.

\section{Pengertian Alat Musik}

Hal ini sejalan dengan pendapat Corazon $\quad(2007: 16)$ mengatakan bahwa :"Castanets (music instrument), representing mechanism yielding voice and have been used to various target. At epoch first castanets also used attendant in dance. In civilization later music instrument used for the entertainment amusement of.

Yang artinya adalah alat musik (musik instrument) merupakan mekanisme yang menghasilkan suara dan telah digunakan untuk berbagai tujuan.

\section{Alat Musik Tradisional}

Menurut Ali (2006:2) yang menjelaskan "Alat musik tradisional melibatkan alat-alat musik khas dari daerah-daerah dan diwariskan secara turun-temurun dari generasi ke generasi”. Alat musik tradisional adalah alat musik khas yang berasal dari suatu daerah tersebut dimana tanpa adanya alat musik modern. Alat musik sangat berkaitan dengan unsur kebudayaan. Unsur kebudayaan berkaitan juga dengan musik tradisional yang ada pada masyarakat.

\section{Organologi}

sesuai dengan pernyataan Sri Hendarto (2011:1) bahwa :

Organologi mempelajari tentang struktur instrument musik berdasarkan sumber bunyi, cara memproduksi bunyi dan system pelarasan. Organologi mempunyai maksud sebagai gambaran tentang bentuk dan rupa susunan pembangunan kontruksi suatu suatu instrument. Sehingga dapat menghasilkan suara seperti alat musik kebanyakan. Organologi dalm istilah musik merupakan "ilmu alat musik “, studi mengenai alat-alat musik.

\section{Pengertian Proses Pembuatan}

Proses merupakan urutan pelaksanaan atau kejadian yang terjadi secara alami atau di desain, mungkin menggunakan waktu, ruang, keahlian atau sumber daya 
lainnya, yang menghasilkan suatu hasil. Menurut Sugono (2008:1218) proses adalah runtunan perubahan (peristiwa) dalam perkembangan sesuatu.

\section{Alat musik Teknik}

\section{Permainan}

Alat Musik Tiup Setiap instrument musik memiliki teknik tersendiri dalam memainkannya, mulai dari teknik permainan yang sederhana hingga teknik permainan yang rumit yang membutuhkan latihan tertentu untuk menguasai teknik permainan tersebut, begitu juga pada permainan alat musik uyup-uyup. Teknik dalam memainkan alat musik merupakan cara atau metode yang dilakukan seseorang untuk menghasikan bunyi yang diinginkan sesuai dengan suara alat musik yang digunakan. Menurut Banoe (2007:409) teknik permainan adalah cara atau teknik sentuhan pada alat musik atas nada tertentu sesuai petunjuk atau notasinya.

\section{Uуир-иуир}

Dalam buku Ben M. Pasaribu (2004:34) Uуир-иуир merupakan alat musik tradisi Mandailing dan termasuk dalam golongan
Aerophone yang cara memainkannya ditiup dan sumber bunyinya berasal dai udara. Uyup-uyup adalah alat musik khas Tapanuli Selatan yang berfungsi sebagai hiburan ketika panen padi tiba, hiburan ketika menghilangkan penat di tengah teriknya matahari di sawah, setelah seharian memanen sawah atau menggembala ternak seperti sapi, kerbau dan kambing

\section{METODOLOGI PENELITIAN}

\section{A. Lokasi dan Waktu Penelitian}

\section{Lokasi Penelitian}

Sesuai dengan judul penelitian "Fungsi Dan Teknik Permainan Alat Musik Tradisional Mandailing Uyupuyup Di Desa Pargarutan Jae Tapanuli Selatan ", Maka penelitian ini dilakukan di Desa Pargarutan Jae Tapanuli Selatan

\section{Waktu Penelitian}

Waktu penelitian dan proses Penelitian dilaksanakan pada bulan Oktober -Desember 2017.

\section{B. Populasi dan Sampel}

\section{Populasi}

Populasi dalam penelitian ini adalah lingkungan rumah narasumber Bapak Baharuddin Siregar. 


\section{Sampel}

Sampel dalam penelitian ini adalah satu pemain alat musik uyupuуup dan lima masyarakat Desa Pargarutan Jae.

\section{Teknik Pengumpulan Data}

\section{Wawancara}

Sesuai pendapat Hadeli (2006:82) mengatakan bahwa: "Wawancara merupakan alat tukar menukar informasi yang tertua dan banyak digunakan umat manusia dari seluruh zaman

\section{Dokumentasi}

Menurut Sugiono (2012:240) mengemukakan bahwa "Photographs provide stringkly descriptive data." Dokumentasi dilakukan untuk melengkapi hasil penelitian yang lebih baik serta untuk kepentingan beberapa hal terkait dengan data yang dibutuhkan.

\section{Observasi}

Observasi yang dilakukan oleh penulis adalah mengamati organology dan teknik permainan alat musik tradisional иуир-иуир di Desa Pargarutan Jae Tapanuli Selatan.

\section{Studi Kepustakaan}

Penulis mencari dan membaca beberapa literatur seperti buku dan artikelnyang relevan dengan pokok yang akan dibahas. Dengan adanya sumber-sumber pustaka tersebut maka dapat diperoleh banyak informasi yang membantu penulis dalam mengerjakan penelitian ini.

\section{Teknik Analisis Data}

Berdasarkan pendapat, maka tahapan analisis data dalam penelitian ini akan diupayakan untuk memperdalam atau menginterpretasi data secara spesifik dalam rangka mendeskripsikan tujuan penelitian.

\section{ISI}

\section{A. Gambaran Umum dan Letak}

\section{Geografis Daerah Penelitian}

Desa Pargarutan Jae merupakan salah satu desa yang ada di Kecamatan Angkola Timur, Tapanuli Selatan, Sumatera Utara, Indonesia. Ibukota kecamatan ini berada berada di kelurahan Pasar Pargarutan.

\section{B. Fungsi Alat musik Uyup-Uyup di Desa Pargarutan Jae.}

Sebagai hasil penelitian dilapangan, alat musik uyup-uyup memiliki fungsi yaitu : 
1. Fungsi Pengungkapan

Emosinal

Musik berfungsi sebagai suatu
media bagi orang untuk
mengungkapkan perasaan atau
emosinya baik itu rasa cinta, kasih
sayang maupun suka-duka.
Berdasarkan dari penelitian yang
sudah dilakukan, alat musik uyup-
uyup dijadikan sebagai wadah untuk
mengungkapkan emosional saat
panen telah selesai. Rasa emosional
ini diungkapkan tidak hanya untuk
panen baik saja tetapi juga untuk
panen yang kurang baik. Hal ini
bertujuan untuk mengungkapkan rasa
syukur atas panen yang sudah
dilakukan.

\section{Fungsi Hiburan}

Dalam suatu karya seni, musik memiliki fungsi sebagai hiburan. Uyup-Uyup ini dimainkan sebagai hiburan ketika panen padi tiba, hiburan ketika menghilangkan rasa lelah di tengah teriknya matahari di sawah, juga setelah seharian di sawah atau menggembala ternak seperti sapi, kerbau dan kambinng.

\section{Fungsi Komunikasi}

Musik memiliki fungsi komunikasi, berarti bahwa sebuah musik yang berlaku disuatu daerah kebudayaan mengandung isyaratisyarat tersendiri yang hanya diketahui oleh masyarakat pendukung kebudayaan terebut. Dari hasil penelitian yang sudah terlaksana uyup-uyup dimainkan sebagai komunikasi untuk memanggil wanita yang ia sukai diseberang sawah. Dan wanita tersebut akan dan segera menjumpai laki-laki yang memainkan uyup-uyup tersebuTT.

\section{Organologi Alat Musik Uyup-uyup}

1. Ambil batang padi yang sudah masak atau menguning dari sawah yang sudah siap panen, kemudian pilih batang padi yang agak besar agar nantinya menghasilkan bunyi yang kuat, karena semakin besar batang padi yang digunakan maka semakin besar pula suara yang dikeluarkan oleh batang padi. kemudian puyuh atau retakkan bagian atas batang padi, agar bisa ditiup 
setelah itu keluarkan getah didalam batang padi seperti butiran sterofom

2. Lubangi batang padi sebanyak 4 lubang dibawah setelah batang padi yang diretakkan (dipuyuh) memakai pisau silet atau duri rumput yang tajam, karena lubang tersebut akan berfungsi sebagai nada yang dikeluarkan oleh batang padi dan pada tahap ini batang padi sudah bisa ditiup tetapi tidak memiliki suara yang kuat dan untuk membuat jarak 4 lubang tersebut sesuai dengan keinginan si pembuat alat musik dan jarak antara lobang yang satu dengan yang lain harus sama.

3. Ambil daun kelapa yang daunnya lebar, kemudian pisahkan daun kepala dari lidi yang ditengah, sehingga daun kelapa menjadi dua bagian.

4. Setelah daun kelapa dan batang padi telah selesai dikerjakan, kemudian lilitkan daun kelapa sampai membentuk corong atau terompet (bagian ujung sampai bagian terlebar daun kelapa) ke bagian bawah batang padi dengan cara melilitkan ujung daun kelapa dan melilitkannya bertangga tangga. Daun kelapa yang digunakan minimal 2 helai jika dibagi dua menjadi 4 helai daun kelapa. Jika 4 helai daun kelapa telah selesai dililitkan kemudian ambil lidi yang telah diruncingkan sebagai pengerat daun kelapa tersebut. Daun kelapa yang dililitkan membentuk corong akan berfungsi sebagai pengeras suara pada batang padi, semakin besar lilitan daun kelapa maka semakin besar pula suara yang di hasilkan dari alat musik uyupuyup.

\section{Teknik Permainan Alat Musik Uyup-uyup}

Berikut adalah teknik bermain alat musik uyup-uyup.

1. Posisi tubuh saat memainkan Uyup-Uyup

Posisi badan dalam memainkan alat musik uyup-uyup dapat dilakukan dengan berdiri 
atau duduk. Menurut narasumber lebih baik memainkannya dengan posisi duduk, dengan alasan lebih mudah untuk meresapi saat memainkannya yang disebut dengan juguk markombang sila.

2. Posisi Meniup Alat musik Uyup-Uyup

Posisi mulut diletakkan di pangkal uyup-uyup kemudian meniup udara yang tersimpan di rongga mulut agar tiupan alat ini tidak mudah habis sehingga pipi si pemain uyup-uyup terlihat membengkak. Posisi bibir diletakkan dipangkal akan tetapi bibir dimajukan sedikit ketengah sampai melewati batang padi yang dipuyuh atau diretakkan. Bunyi yang keluar merupakan dari batang padi, tiupan yang kuat akan sangat berpengaruh untuk keras lembutnya suara yang dihasikan dari batang padi. Sedangkan daun kelapa yang berbentuk corong hanya sebagai pengeras suara saja.

3. Posisi Jari-Jari Tangan Saat Memainkan Uyup-Uyup
Posisi jari-jari tangan saat memainkan uyup-uyup masingmasing di lubang nada. Jari tangan kiri diletakkan di batang padi/ uyup-uyup dengan jari telunjuk di lubang atas dan jari tengah tepat dibawah jari telunjuk. Kemudian diikuti dengan jari telunjuk tangan kanan dan jari tengah dibawahnya sama seperti tangan kiri. Tinggi rendahnya nada yang dihasilkan dari alat musik uyup-uyup merupakan dari penjarian seperti kalau pemain uyup-uyup ingin nadanya tinngi pemain uyup-uyup cukup menutup dua lubang saja dan jika nadanya ingin rendah pemain uyup-uyup cukup menutup tiga atau empat lubang.

\section{PENUTUP}

Berdasarkan hasilpenelitian yang telah dilakukan, makapenulis membuat beberapa kesimpulan diantaranya :

1. Uyup-Uyup adalah nama alat tiup yang berasal dari daerah Tapanuli Selatan yang terbuat dari batang padi yang sudah 
menguning dan daun kelapa juga sering dimainkan oleh petani petani setelah panen tiba. Uyup-uyup ini juga digunankan untuk menghilangkan rasa jenuh saat berada di sawah. Hal yang unik adalah pada saat meniup Uyup-uyup merupakan tanda memanggil lawan jenisnya di seberang sawah dan dengan sendirinya lawan jenisnya akan segera mendatangi si pemain Uyup-uyup. Uyup-uyup termasuk klasifikasi aerofon (reed instrument) dengan menggunakan badan atau alat musiknya sebagai sumber bunyinya.

2. Fungsi Uyup-Uyup adalah sebagai 1. Musik berfungsi sebagai suatu media bagi orang untuk mengungkapkan perasaan atau emosinya baik itu rasa cinta, kasih sayang maupun suka-duka. Berdasarkan dari penelitian yang sudah dilakukan, alat musik uyupuyup dijadikan sebagai wadah untuk mengungkapkan emosional saat panen telah selesai. Rasa emosional ini diungkapkan tidak hanya untuk panen baik saja tetapi juga untuk panen yang kurang baik. Hal ini bertujuan untuk mengungkapkan rasa syukur atas panen yang sudah dilakukan.

3. Teknik permainan pada alat musik Uyup-uyup terdiri dari posisi badan dalam memainkan alat musik tradisional Mandailing Uyupuyup,penjarian nada dan teknik memainkannya. Posisi badan dalam memainkan uyup-uyup dapat dilakukan dengan berdiri duduk dengan sikap tegak dan tidak membungkuk. Posisi mulut diletakkan diujung pangkal atas uyup-uyup dan jari-jari tangan masing-masing di lubang nada. Untuk penjarian nada dalam memainkan uyupuyup jari jari tangan harus berfungsi dan peka menurut bagiannya masing-masing

4. Uyup-uyup hanya tahan 5 jam saja, karena bahannya yang sangat gampang layu. 


\section{DAFTAR PUSTAKA}

Aruan, Maria Agustina (2017).

Skripsi "Fungsi dan Teknik

Permainan Ansambel Musik

Genderang Si Sibah Pada

Masyarakat Pakpak di Kabupaten

Dairi : SKRIPSI UNIMED

Ben, Pasaribu M. 2004. Pluralitas Musik Etnik. Medan: Universitas HKBP Nomensen.

Corazon, CD. 2007. Traditional Musical Instrument of The Philppine. Nevada: FMAdigest

Damanik, Risna, Margaretta (2014) "Teknik permainan Alat Musik Tradsional Simalungun Tulila : SKRIPSI UNIMED

Hadeli. 2006. Metode Penelitian Pendidikan. Padang Quntum Teaching

Jansen, Arlin Dietrich. 2003. Gonrang Simalungun, Struktur dan Fungsinya dalam masyarakat Simalungun. Medan : Bina Media

Leach, Maria.2001. The new book of knowlwdge. New York: glorier, Inggris
Maryaeni, 2005. Metode Penulisan Kebudayaan, Jakarta. Bumi Aksara

M.A, Hadeli, Drs. 2006 Metode Penelitian Kependidikan. Ciputat: PT. Ciputat Press

Merriam, Alan P. 1964. The Anthopology Of Music. Evanston IIIionis: North Western University Press.

Moleong, Lexy.2008 Metodologi Penelitian Kualitatif. Bandung: PT. Remaja Rosda Karya.

Mulya. Aqsa (2016). Skripsi “Teknik Permainan Gendang etek dalam mengiringi lagu dangdut pada grup musik teluk Aru di Pangkalan Brandan : SKRIPSI UNIMED

Prawijaya, Agus 2017. "Instrumen saleot di tapanuli selatan kajian terhadap organologo, fungsi dan teknik permainan : SKRIPSI UNIMED

Handarto, Sri. 2011 Metode Penelitian Kebudayaan. Jakarta. Bumi Aksara 
Sugiyono. 2009. Metode Penelitian

Kualitatif. Bandung: Alfabeta.

Sugiyono. 2010. Metode Penelitian

Kebudayaan . Bandung. CV

Alfabeta

Sugiyono, Dr, Prof. 2012 Metode

Penelitian Kuantitatif kualitatif dan $R \quad \& \quad D$. Bandung:

ALFABETA

Tohirin, Dr. 2013 Metode Penelitian Kualitatif Dalam Kependidikan Dan Bimbingan Konseling. Jakarta: PT RAJAGRAFINDO PERSADA 